\title{
Un método para analizar los procesos de concentración mediática
}

\section{A method to analyze the processes of media concentration}

María José Pérez Serrano. Universidad San Jorge

Recibido: 6-I-2010 - Aceptado: 14-IV-2010

Resumen:

En estas páginas se propone un modelo de análisis de casos de concentración mediática basado, principalmente, en el estudio de la propiedad y el reparto de capital social. Se elige este punto de vista ya que la base para medir la concentración de un modo lo más real posible no es conocer los márgenes marcados por la ley, sino determinar quién posee el control efectivo de la empresa de comunicación. El modelo planteado se estructura en cuatro fases: un planteamiento inicial, una fase jurídico-empresarial, una fase analítico-periodística, y un corolario, que refleja el nuevo mapa mediático tras el proceso.

Palabras clave:

Método, metodología, concentración de medios, empresa de comunicación, Ciencias de la Comunicación.

Abstract:

On these pages we propose a model for analysis of cases of media concentration based mainly on the study of ownership and equity sharing. We choose this point of view as the basis for measuring the concentration of a real way because we think that know the margins set by the law is not useful for this approach and determine who has effective control of the media business yes. The suggested model is structured in four phases: an initial approach, a legal-corporate phase, an analytical-journalistic phase, and corollary, which reflects the new media map after the process.

Key Words:

Method, Methodology, Media Concentration, Media Business, Communication Sciences. 


\section{Planteamiento introductorio}

\subsection{El valor de una disciplina}

La creciente integración de los medios de comunicación en la estructura económica mundial implica la necesidad de su análisis empresarial ya que aporta valiosas herramientas para entender parte de la estructuración y dinámica de ese entorno. Y esta premisa conduce, a su vez, a definir el concepto de empresa de comunicación como un constructo teórico que emana del estudio sistematizado de los elementos, estructura, funciones y funcionamiento de las organizaciones cuyo objeto resulta ser la información en sentido amplio. En el contexto académico, se trata de un corpus teórico inserto en los estudios de Comunicación cuyas ramificaciones exigen un conocimiento interdisciplinar de un mundo más que cambiante. Por ello, la conceptualización de este tipo de empresas se apoya en tres pilares fundamentales: el derecho, la economía y el periodismo o, expresado con un sintagma más vanguardista, las ciencias de la comunicación. Bajo este prisma, la ausencia de alguno de estos tres soportes supondría un estudio incoherente, incompleto y carente de perspectiva global.

La razón última de estas tres disciplinas -y no otras- surge de la comprensión de sus principios básicos. El Derecho porque, según Stammler (1930), es la voluntad vinculante, autárquica e inviolable, y nos aporta el marco legal necesario donde se desenvuelven las empresas. La Economía, por ser "la ciencia que estudia los métodos más eficaces para satisfacer las necesidades humanas materiales, mediante el empleo de bienes escasos, es decir, la administración eficaz y razonable de los bienes"; y las Ciencias de la Comunicación, ya que es su natural campo de estudio, donde el discente y futuro profesional desempeñará su labor suprema de contribuir al logro de uno de los derechos principales de los seres humanos: recibir una información libre y veraz. La confluencia de estas ramas del saber se traduce en un planteamiento de conjunto cuyo objetivo es el conocimiento de una empresa de comunicación desde su génesis hasta su final, a través de un proceso de liquidación, o hasta su transformación, mediante un proceso de concentración.

Siguiendo con el argumento y dado que dos de los ejes principales que atraviesan "los medios de comunicación convencionales son la tendencia a la concentración” (Corominas; Moragas, 2002: 1) y, consecuentemente, la propia fortaleza emergente de los grandes grupos de comunicación, que no sólo forman parte de las estructuras de poder, sino que son imprescindibles como vehículos de comunicación de los que se sirven quienes dirigen la sociedad en todos sus órdenes, el estudio de este segmento conceptual, cuya superestructura -recordemos- es la Empresa de Comunicación; y la circunscripción epistemológica al estudio de casos de procesos de crecimiento externo no es cuestión menor; antes al contrario, resulta 
vital para comprender el estado de los medios, tanto en su vertiente empresarial, en constante mutación, como en la estructura y dinámica comunicativa. Más aún, teniendo en cuenta que la concentración empresarial, en general, y la informativa, en particular, es un fenómeno que tiene acusada relevancia y actualidad, tanto para la configuración empresarial del sector informativo, como para la adecuada efectividad del derecho del ciudadano a recibir una información sin sesgos.

Es cierto, sin embargo, que el fenómeno ha sido, en los últimos tiempos, bibliográficamente muy tratado, pero se observa un vasto campo de investigación, aún por escrutar, en lo que concierne al estudio pormenorizado de los casos e, incluso, se echa de menos un paradigma analítico adecuado para aplicar a dichos procesos y que, también, sirva de pauta para sustentar, por un lado, la fundamentación teórica y, por otro, una medición empírica.

\subsection{Objetivos y meta-metodología}

Aunque los grupos de comunicación proyectan, en muchas ocasiones, estrategias de crecimiento externo basadas en fundamentos netamente económicos que, al final, influyen en sus principios configuradores y, además, se insertan en la lógica del mercado, donde hay, asimismo, líneas políticas con las que divergen o convergen, y pese a la dificultad intrínseca del tema, podemos centrar la finalidad de estas páginas en delinear un modelo que sea extrapolable y apto para los procesos de concentración, intentando que las peculiaridades nacionales o internacionales no le resten validez.

Por tanto, no partimos, como suele suceder en un trabajo científico, de una declaración conjetural, una proposición tentativa acerca de las relaciones entre dos o más fenómenos o variables, es decir, de una hipótesis; sino que nos apoyamos en las razones que, según Kerlinger y Lee (2001: 14, 24-25), avalan su importancia en la investigación científica, si bien, en esta ocasión, aplicadas al método; a saber: puede deducirse a partir de la teoría; es posible someterlo a prueba y demostrar que es probablemente verdadero y útil, y es una herramienta poderosa para el avance del conocimiento, porque permite al científico ir más allá de sí mismo.

En resumen, en este trabajo, el método se convierte en hipótesis y, para detallar la forma de proceder y, consciente de que, en muchas ocasiones, concentrarse en lo metodológico quizá no resuelve ninguno de los problemas con que tropieza el investigador -pero, "al menos, le ayuda a detectarlos" (Buchanan, 1979: 37) se aplicará el método científico; se incidirá en el hipotético-deductivo para su claridad y rigor intelectual, y se completará con una ejemplificación que servirá para sustentar sus conclusiones. 
Quedan, pues, fuera de interés de este trabajo abordar los procesos económicos para interpretar la ideología de los mensajes, y también buscar la especificidad de esos procesos, ni siquiera formular un concepto válido de concentración de medios de comunicación basado en la propiedad (aunque será apuntado a lo largo del mismo); sino utilizar la perspectiva "micro" para, aportando sólidos basamentos filosófico-científicos, enunciar un modelo ${ }^{1}$ de análisis de caso de concentración de medios. Y, fijándose en una cierta ambición "retórica", servir de ayuda en la justificación de un método en las ciencias sociales relacionadas con la comunicación. Así, la metodología se convierte, no en utillaje, sino en referente del discurrir investigador.

\section{Una metodología para las ciencias de la comunicación}

\subsection{Fundamentos lógicos: base del método}

En muchas ocasiones, la propia secuencia discursiva constituye el primer pilar científico de la investigación por cuanto trata de fijar unos principios que, ante la multiplicidad de perspectivas en que el quehacer humano puede darse, permitan un desarrollo ordenado y sistemático del trabajo. Pero cualquier investigación, para delimitar su campo de estudio, fijar las coordenadas de su discurrir, procurar claridad expositiva, suscitar interés y establecer conclusiones válidas, necesita la aplicación coherente de un método, vocablo que aúna camino y meta: el trayecto para la demostración de la verdad y conseguir el conocimiento científico. Es decir, el camino, trazado ordenadamente según un plan definido, tanto en el proceso como en la determinación de los objetivos finales, que conduce a la ciencia.

La elección de ese método concreto, implica el concepto previo de Metodología como ciencia, es decir, el estudio sistemático de los métodos utilizados por una disciplina para su investigación, estructuración, análisis y proyección ordenada de la verdad. En esta línea, la metodología constituye un modo de realizar el análisis sistemático de los principios racionales que guían los procesos de adquisición de saberes epistémicos, así como los procesos de configuración de los contenidos de una ciencia o disciplina en sus estructuras, articulación y conexiones temáticas. Diferenciar método (modo de trabajo guiado por reglas), metódica (conjunto de reglas canónicas sobre el empleo de ciertos métodos) y metodología (teoría que in-

\footnotetext{
Según Medina (2005: 99) se denomina modelo al esquema teórico de un sistema o de una realidad compleja, que se elabora para facilitar su comprensión y el estudio de su comportamiento y su estudio, así como el examen histórico de las distintas teorías contribuye a comprender las intenciones, los resultados, los problemas y los instrumentos o técnicas que ayudaron a solucionarlos en el arduo trabajo de hacer progresar el conocimiento (Rodríguez de Rivera, 2006).
} 
cluye todos esos campos) puede ayudar a una limpieza intelectual en la estrategia a seguir en un trabajo de investigación.

La claridad conceptual exige, además, trazar la diferencia entre epistemología y metodología. El vocablo helénico epistêmê designa un conocimiento firme (contrapuesto a la doxa) y se refiere al conocimiento filosófico (reflexión sólida) sobre el mismo conocimiento o sobre el cómo llegamos a conocer, en qué condiciones, etc. La Metodología se refiere también a conocimientos, pero no en cuanto operaciones o contenidos mentales, sino en cuanto se generan, desarrollan, o se confirman cuestiones siguiendo determinadas instrucciones o métodos. En el caso de métodos para el conocer (en ciencia, en análisis filosófico, en crítica de filosofía social), la metodología los examina en sus fundamentos, en la consistencia de sus reglas, etc. Ambas se encuentran, por así decirlo, ligadas intrínsecamente por su propia naturaleza: la epistemología remite a la "filosofía" de cómo llegamos a conocer la realidad; la metodología se refiere en primer lugar a la práctica.

Por todo ello, es básico entender que en un trabajo, en un análisis como puede ser el de un caso de concentración, la metodología procura responder a la premisa científica, conscientes de que la diversidad de opciones exige una adecuada correspondencia entre cómo se concibe la realidad que se estudia, la interrelación de datos, su forma lógica de análisis, y la estructura para su exposición y obtención de conclusiones.

\section{2. "Filosofía metodológica": un concepto detrás de una teoría}

Metodología es, por tanto, una parte de la lógica general que estudia los métodos de las ciencias, y metodología científica, en particular, es aquella parte de la teoría general de la investigación científica que se ocupa de los métodos seguidos y a seguir (Giner, 1988). Trata de establecer un camino que evite la suerte o el azar y que ayude a resolver no sólo el cómo hacer (know-how), sino los fundamentos, los por qué (knowwhy); o sea, procura dominar el "método" de solución de cualquier problema, tanto en su vertiente práctica como conceptual o teórica; y, por consiguiente, una de sus funciones consiste en ayudar a la evaluación de las teorías ya existentes (Rodríguez Rivera: 2006).

Hace casi cuarenta años, Imre Lakatos (1971) formulaba la siguiente máxima: "la filosofía de la ciencia, sin historia de la ciencia, es algo vacío; la historia de la ciencia sin filosofía de la ciencia es ciega”. Poco después, Hilary Putman afirmaba que "la filosofía de la ciencia es -ella misma- una ciencia empírica" (Suppe, 1973: 513). En una línea de pensamiento cercana y, por supuesto, sin ánimos comparativos, insistimos en la búsqueda del método también para los casos de concentración. Para ello, aunque sea mínimamente, hay que 
ser consciente de lo que hemos denominado una "filosofía metodológica", que no es otra cosa que un breve perfil retrospectivo sobre la evolución histórica de la metodología como ciencia. Esto conseguirá, por un lado, dar más consistencia a nuestro objetivo y, por otro, contribuir a nuestra segunda meta, que no es otra que servir de ayuda en la justificación de un método en las ciencias sociales relacionadas con el estudio de la empresa de comunicación.

Ese promenade por la "filosofía metodología" podría comenzar por los clásicos griegos, que, en su preocupación por conocer y transmitir la verdad, cultivaron el pensamiento crítico, razonado, metódico. Sócrates, con su triple proceso (ironía, inducción y mayéutica) para alumbrar la verdad, fue el creador del método eficiente para desmontar las teorías sofistas; Platón con su episteme, saber construido metodológicamente en oposición a las opiniones individuales, y Aristóteles, constituyen el triángulo filosófico y del método que subsistirá a través de la escolástica hasta la evolución del siglo XVII derivada de las ideas del Renacimiento. Y podría llevarnos a la diferenciación entre las tres orientaciones metodológicas fundamentales de la filosofía contemporánea:

a) El método trascendental, kantiano, que consiste en el análisis de las condiciones y límites del conocimiento, actitud epistemológica esencialmente crítica.

b) El método hegeliano adoptado por el marxismo desde un punto materialista y aplicado principalmente a la Historia.

c) El método fenomenológico, de Husserl, de tendencia existencialista.

Mas siendo conscientes de esa necesidad y del acuerdo común del imprescindible rigor científico en la exposición de ideas en los trabajos de investigación sobre las ciencias de la comunicación, el problema es que, a la hora de implementarlas en estudios y tratados sobre los medios, quedan relegadas, nunca mejor dicho, al mundo "platónico". En diversas ocasiones, tesis, ensayos, comunicaciones, investigaciones... sobre estos temas se observa la carencia de un corpus metodológico complejo y completo, caleidoscópico, útil y versátil que ayude a fundamentar aquello que las ciencias naturales tienen incorporado desde antiguo. Muchas veces se emplean sentencias del tipo "en el discurrir del estudio se aplicará el método científico", sin determinar en qué consiste y, por supuesto, sin focalizarlo y constreñirlo, como es el caso que nos ocupa, a la problemática empresarial de los medios, donde las dificultades se acrecientan, ya que la historia y la matemática, por ejemplo, siendo imprescindibles, resultan insuficientes. 


\section{Modelo de análisis de la concentración de medios}

Tratar sobre la concentración mediática exige entender, primero, que su sentido no estaría completo si estuviera falto de un basamento teórico sobre la definición de concentración, sus causas y consecuencias, así como, y quizá más importante, si se obviara su repercusión en el mercado de la información y su influencia sobre el pluralismo informativo; y, segundo, la praxis, es decir, si no se analizaran casos que ejemplifiquen los supuestos teóricos desarrollados.

La conjunción de ambos planos da una resultante homogénea como base operativa. No obstante, el planteamiento que presentamos a continuación se encuentra desglosado porque si, en bastantes ocasiones, se ha aportado teoría, es en la vertiente práctica -bastante menos tratado bibliográficamente- donde falta, como se propone desde las primeras páginas, un método de análisis de casos específicos².

\subsection{El método científico: propuesta de aplicación a las investigaciones sobre concentración de medios}

En la base teórica de la investigación se debe partir, tal como lo han hecho diversos investigadores, del modelo de McQuail (1992), del cual se colige que, a partir de una sociedad determinada, se configura un sistema de medios que viene también delimitado por un conjunto de políticas. Se trata de un modelo secuencial de causa-efecto. La estructura de medios implica, en primer lugar, el desarrollo de una estrategia concreta o conducción, que se concreta en un conjunto de acciones que, a su vez, afectan a la sociedad de forma global, incluidos los aspectos económicos y culturales. En este sentido, "el papel de la investigación es la de diagnosticar o proporcionar información sobre las acciones y efectos de la estructura de medios sobre la sociedad para así influir en la definición de políticas" (Llorens Maluquer , 2001: 13).

Por su parte, a la tarea de conciliar ese binomio (concentración de medios - repercusión en el mercado de la información y su influencia sobre el pluralismo) se ha de aplicar una metodología que permita conocer la realidad según las distintas fuentes, el análisis de sus relaciones parciales y una objetivación sistemática que posibilite una conclusión válida. Aquí incide el método hipotético-deductivo, cuya descripción esquemática de fases nos indica la posibilidad de aplicación:

2 Antes de desglosarlo es preciso indicar también que, para una mayor comprensión, el análisis de casos está inserto, como se verá a continuación, en el apartado 4 ("Contrastación de la hipótesis y de las consecuencias"). Se hace, simplemente, para que el lector tenga una visión global del "para qué” se hace el análisis y donde estaría, aunque, insistimos, es perfectamente extraíble (y así se recomienda) para hacer un análisis de caso aislado. 
1. Fase inductiva: descubrimiento y planteamiento del problema. Premisas reales para determinar hechos e inferir consecuencias:

- Se han llevado a cabo estrategias de crecimiento externo en las empresas de comunicación estudiadas.

- El hecho se produce en un marco legal, nacional y comunitario, que incide sobre lo estrictamente empresarial o mercantil.

2. Hipótesis: ¿Puede tener consecuencias en el mercado de la información?

3. Deducción: Este hecho repercute en los destinatarios de la información si entendemos que limita el pluralismo.

4. Contrastación de la hipótesis y de las consecuencias.

5. Confirmación de la hipótesis: el supuesto se convierte en teoría o ley (Múñoz, et al. 2001: 221).

En esta línea metodológica, se debe aplicar la secuencia de las leyes generales del método científico, que parte de la enunciación de interrogantes que abran paso a iniciales juicios que se pueden estimar como probables, fundados en indicios o datos que, naturalmente, son incompletos; es decir, conjeturas que, posteriormente, podrán ser contrastadas por los descubrimientos de la realidad. Estas leyes son las siguientes:

- $\quad$ Proceder a la investigación de lo que nos es más conocido a lo más desconocido;

- $\quad$ Avanzar por grados, de forma que cada una de las conclusiones siga inmediatamente a sus principios próximos;

- Que haya conexión entre todos los grados de la serie progresiva de las verdades, para que no se intercale ninguna proposición inconexa, conducirá a la formulación de las diferentes cuestiones que, “a priori”, nos darán la hipótesis.

En definitiva, seguir los principios cartesianos (Descartes, 1980) en el transcurso de la investigación a fin de alcanzar una conclusión válida (evidencia, división, gradación y revisión).

El método, pues, "es el camino más seguro para llegar a la verdad y su necesidad se manifiesta por el fin que queremos conseguir". Su aplicación en la investigación es imprescindible y exige poner en práctica procedimientos cada vez más complejos y rigurosos para lograr una mayor eficacia en el trabajo intelectual, lo que implica conjugar el método analítico, que consiste en descomponer; pasar del todo a sus partes, del 
efecto a la causa, de lo concreto a lo abstracto, y el método sintético, que trata de componer, reunir, pasar de las partes al todo, de la causa al efecto, de lo abstracto a lo concreto.

Así, el método científico, base del trabajo, usa de ambos: el análisis constituye el proceso lógico que el entendimiento sigue para la adquisición de la ciencia y la síntesis es el modo de cómo debe exponerse y transmitirse. Y, como ninguna disciplina los utiliza con exclusividad (Latorre; Rubio, 1965), ambos métodos se complementarán con el método deductivo ${ }^{3}$ y el inductivo ${ }^{4}$. Es obvio que el catálogo de métodos de estudio e investigación es más amplio; pero, recordemos, el objetivo de esta propuesta no es sino cimentar de forma sólida y coherente el devenir definido y concreto de los análisis de concentración de medios.

\subsection{Modelo de análisis de casos de concentración de medios}

Una vez conscientes del marco metodológico a utilizar, hay que precisar deductivamente, en qué consiste y cómo se desarrolla. En un primer estadio, la dificultad existente para determinar parámetros cuantitativos inclina a escoger la concentración de la propiedad y el reparto de capital social de las empresas de comunicación como fuentes referenciales, aunque sin obviar totalmente otros factores como la concentración de audiencias derivadas de la reducción de medios, la inversión publicitaria, y la incidencia de la tecnología en las expectativas de concentración (Iglesias, 2005). Se optará por ella, es decir, servirá de eje a las demás, ya que la base para medir la concentración de un modo lo más real posible, no es conocer los márgenes marcados por la ley, sino saber quién posee el control efectivo de la empresa.

A continuación y, poseedores de ese peculiar prisma, habría que considerar que esta disección debería tener como base el estudio comparativo de los datos empresariales previos y posteriores al momento de la concentración y el análisis de contenido ${ }^{5}$ de los medios de comunicación impresos, cabecera de los grupos que lideran el proceso $^{6}$. Dicho de otro modo, para que este estudio se produzca con un objetivo globalizante e

3 Proceso intelectual que parte de verdades universales para obtener otras particulares o menos universales; de la observación del objeto, del análisis y combinación de cada una de sus partes, obtiene las primeras conclusiones

4 El entendimiento para fijar y vertebrar conceptualmente el decurso del estudio parte de antecedentes singulares a fin de descubrir verdades universales: observación del hecho cuya ley se quiere investigar; hipótesis o formulación de una explicación provisional; experimentación: trata de comprobar la hipótesis mediante una serie de operaciones científicamente establecidas, e inducción: formula la ley general, extendiendo a todos los casos de igual naturaleza la relación comprobada en el caso particular.

5 Este análisis podría ser completado con la formulación de un "tesauro" con los términos vinculados a la concentración que sirviesen como criterios o categorías para la clasificación de cada una de las expresiones, frases y textos relacionados con este asunto. La formulación, planteamiento y universalización de este tesauro se plantea aquí como un apoyo investigador y su conceptualización pragmática excede a los cometidos de estas páginas. Si se llevase a efecto, el análisis de contenido se pautaría y se objetivaría, aún más, esta fase.

6 En este sentido son relevantes las investigaciones del Centre d'Étude des Discours, Images, Textes, Écrits, Communications (CÉDI- 
integrador es preciso adoptar una perspectiva empresarial y económica, pero considerando, también, la vertiente legal, jurídico-administrativa, política y social del tema objeto de estudio, y su repercusión sobre la pluralidad informativa. Se trata, pues, de conocer y analizar, tal vez con inevitables limitaciones, procesos de concentración en cuyo estudio se emplearían recursos bibliográficos y de naturaleza jurídico-administrativa, más los textos legales aplicables en el momento, y su reflejo, y disección, en los medios impresos. Pero si los útiles se tienen claros, la incógnita surge al plantearse cómo proceder a su disposición para conseguir resultados universalmente válidos, es decir, para lograr un método que se convierta en un modelo teórico ${ }^{7}$, como el que planteamos a continuación.

La metodología específica por la que se apuesta en estas páginas y que se utilizará para conocer en profundidad una situación concreta de concentración de medios, entendiendo por tal "la acción y el efecto de aglutinar empresas de comunicación bajo una misma corporación que puede afectar a la efectiva libertad de comercio, expresión, difusión y elección por parte del consumidor-receptor entre los diversos productos que concurren en el mercado de la información” (Pérez Serrano, 2007: 470), se sirve, como base, del método científico y se desglosa en las siguientes fases:

1. Planteamiento inicial: Apoyándose en el método deductivo, se hace una breve introducción descriptiva de la situación empresarial que se estudia. En ella se aportarán pautas genéricas del medio (radio, prensa, televisión, internet) al que se refiere el proceso, que ayudarán al investigador a situarlo en sus coordenadas locales, temporales y sociales.

2. Fase jurídico-empresarial:

2.1. Es preciso analizar desde un punto de vista de estructura económica del grupo de comunicación, la sociedad y la unidad de negocio protagonista de la concentración.

2.2. Una vez conocido el environment empresarial de la unidad económica se pasará a una descripción histórica y pormenorizada de las iniciativas de gestión conjunta, previas al acuerdo de concentración. Se detallará la importancia y el papel de sus protagonistas, ya que, en muchas ocasiones, estos procesos están estrechamente vinculados con las personas físicas dueñas (o representantes) del "poder de informar" derivado de la actividad comunicativa.

TEC) de la Université de Paris, cuyos trabajos tienen su reflejo en la Revue Mots, les langages du politique, entre otras publicaciones

"Una teoría es un conjunto de constructos (conceptos) interrelacionados, definiciones y proposiciones que presentan una visión sistemática de los fenómenos al especificar las relaciones entre variables con el propósito de explicar y predecir los fenómenos” (Kerlinger; Lee: 2001: 10). 
2.3. A continuación, se describirán los límites, condiciones y operaciones de canje (acciones) definitivos del proceso, en términos matemáticos, así como su incidencia en las consecuencias de dichas operaciones, también en cuanto a la difusión, tirada, audiencia, etc.

2.4. La fase siguiente hará énfasis en el proceso jurídico que, normalmente, acompaña a los procesos de concentración. Es decir, habrá que realizar un "paseo" por las instituciones de defensa de la competencia (Agencia de Defensa de la Competencia) y por las decisiones jurídicas, sentencias, autos, etc. que conducen a la aprobación, o no, de la concentración. Este recorrido analítico se deberá ajustar a la normativa, y a la actualización constante, en torno al entramado jurídico que guía la competencia leal y la concurrencia legal de las empresas en una economía de libre mercado, que tiene por objeto el respeto de los derechos y libertades del ciudadano, que, en el caso de las empresas de comunicación, será un receptor individual o la audiencia en su conjunto.

3. Fase analítico-periodística:

3.1. Expuesto el panorama empresarial, da comienzo el análisis de las actitudes y posturas de la prensa ante la concentración, que serán los referentes y soportes de análisis (línea informativa y editorial de los medios, opiniones de columnistas, etc.). Dado el lenguaje empleado en el "metaperiodismo" (noticias que hablan de medios de comunicación), la dificultad esencial reside en penetrar en ese complejo mundo de las ideas y la subjetividad que entrañan, máxime cuando la óptica desde la que se emiten, o la perspectiva desde la que se contemplan, son dispares y la labor investigadora ha de procurar darles una interpretación ecuánime en función de los parámetros de la investigación.

El objetivo de esta parte, basada en un análisis de contenido complejo (acompañado y apoyado por tecnologías como el programa SPSS -Statistical Annalysis Software- y el Aquad -Analysis of Qualitative Data-), es destacar las diferencias en el modo de informar, de opinar y de editorializar sobre el proceso de concentración del periódico cabecera del grupo de comunicación protagonista del proceso y de sus rotativos "adversarios", así como otros medios, incluidos en los de más tirada y, según el European Opinion Leaders (ABC, 15 de noviembre de 2000), de más influencia y credibilidad. En España, por ejemplo, la recopilación de lo publicado por los diarios más importantes, en los días claves de los procesos, vertebrarían este análisis que pretende incluir los distintos aspectos de los géneros periodísticos de modo sencillo y breve, abarcando el horizonte más amplio posible desde las siguientes perspectivas: 
a) Consideración de antecedentes, más o menos próximos en el tiempo.

b) Selección de las noticias, editoriales y columnas dentro del periodo fijado con inclusión de gráficos sobre la frecuencia con que aparecen. Este periodo deberá determinarse en función de las fechas claves del proceso. Como recomendación se podría situar la primera de las fechas en el día en que algunos de los periódicos da alguna pista inicial sobre el proceso.

c) Análisis de los géneros, que conjugará:

- Lo que se denomina "superestructura informativa”; es decir, el ángulo desde el que se analizarán las características básicas de la información en general con aplicación de los principios teóricos a la praxis de esta investigación.

- El análisis diacrónico de los hechos noticiosos y la sincronía del estudio según la ubicación de la noticia, crónica o comentario, considerando las características icónicas, paralingüísticas (especialmente, titulares) y lingüísticas, así como una valoración del contenido, incidiendo en las funciones y disfunciones del género informativo y si las tesis expuestas se adecuan a principios configuradores (Nieto, Iglesias: 2000: 144) de los diarios. El análisis de los editoriales partirá de su lectura reflexiva, el contexto en que aparecen, la concreción temática o tesis, la determinación de su estructura, el estudio de la forma a partir del tema y la conclusión. Para evitar reiteraciones, se omitirá, a veces, la referencia a algunos apartados. Esta disección de los géneros informativos trata de delimitar los elementos que componen el mensaje periodístico y las inapropiadas incursiones de la opinión en la información.

3.2. Aplicación del método estadístico. En este punto se ha de sistematizar en cada caso qué tipo de método se emplea y sus interrelaciones, encuestar a los lectores, y saber, desde el punto de vista de los principios configuradores, si se ha reducido o no el pluralismo (también se pueden averiguar de la misma forma los efectos sobre los periodistas). Así, la estadística forma parte de los análisis previos realizados de cada empresa en número de acciones, opiniones, difusión, etc.; se ordena y tabula todo el proceso, y se suple el déficit existente que es el desconocimiento de si el pluralismo teórico es entendido o recibido por el receptor. Así se minimiza el riesgo de la falta de datos objetivos (fuera de los económicos) y, además, se completan todas las fases de un proceso de comunicación tradicional. Más aún, teniendo en cuenta que los más recientes estudios sobre concentración de medios inciden en la importancia de conocer cómo el receptor percibe los procesos y si éstos influyen -y cómo- en aquellos. 
4. Corolario: se debe plantear un perfil del nuevo mapa del sector mediático en que se ha desenvuelto la concentración, es decir, cómo queda y qué sucede después del proceso.

En el ámbito español, si se aplicara este método, por ejemplo, a la concentración de Canal Satélite Digital y Vía Digital en Digital +, que comenzó el 8 de mayo de 2002 con la firma el acuerdo entre Sogecable y el grupo Admira Media, S.A. para la integración de la plataforma multicanal de televisión de pago Vía Digital en Sogecable, mediante una ampliación de capital de ésta, el esquema que seguiría sería el siguiente (Pérez Serrano, 2006):

\section{CONCENTRACIÓN DE CANAL SATÉLITE DIGITAL Y VÍA DIGITAL EN DIGITAL +}

1. Punto de partida.

2. Situación de Canal Satélite Digital al producirse la concentración.

3. Situación de Vía Digital en el momento de producirse la concentración.

4. Rasgos definitorios de los grupos inmersos en el proceso.

Grupo PRISA.

Admira, del grupo Telefónica.

5. Concentración de las dos plataformas de televisión digital por satélite.

6. Legislación y jurisprudencia aplicable.

7. Criterio de los órganos de Defensa de la Competencia (Agencia de Defensa de la Competencia), así como decisiones del Gobierno mediante acuerdos del Consejo de Ministros o resoluciones del Ministerio de Economía y Hacienda.

8. Actitud y opinión de la prensa ante la concentración de Vía Digital y Canal Satélite Digital.

9. Percepción por parte de la audiencia del proceso. Análisis estadístico y comparación con los principios configuradores.

10. La nueva postura de la televisión digital tras la concentración.

Este planteamiento no es sino una pretensión, un modelo, un enfoque, una propuesta, una manera, una sencilla y simple aportación para resolver un problema, considerando -como decía Borges (2004)- que 
"pensar es olvidar diferencias, es generalizar, abstraer". Plantear ese problema supone utilizar el lenguaje, que no sólo sirve -como señalaba Karl Popper (1997)- para vehicular emociones y estímulos, no sólo para expresar y comunicar, sino para entablar pretensiones de verdad y validez. Y conocerlo es poner en práctica un método que permite no sólo enunciar claramente los problemas, proponer soluciones y examinarlas, analizar las consecuencias lógicas de cada propuesta o esforzarse por echar abajo cada solución en lugar de defenderla, sino que también consiste en averiguar qué han pensado y dicho otros acerca del problema en cuestión, por qué han tenido que afrontarlo, cómo lo han formulando y tratado de resolver (Harada, 2005).

Esto es lo que ahora toca hacer en estos momentos en que, desde diferentes esferas, se exige dar un paso más en el cientificismo de nuestros estudios y donde se detecta una falta de metodologías específicas para las ciencias de la comunicación y, según algunos profesores, como Jacques Guyot, se impone una profundización más intensa en áreas como la economía política de las industrias culturales, tanto en el ámbito público como privado.

\section{Consideraciones finales}

La regulación por omisión o desregulación; la privatización; las formas de competencia imperfecta del mercado, es decir, los monopolios y oligopolios como formas naturales en algunos medios y la desmonopolización, en otros casos; la convergencia, y la globalización son, junto con la concentración, algunos de los fenómenos que caracterizan, en la actualidad, a la industria de la comunicación.

En España, esta industria tiene una incidencia en la economía en torno al 5 \% del PIB (Campos Freire, 2007) y, en ella, como punta de lanza de todos los cambios posibles, las empresas informativas tradicionales han dado paso a grandes conglomerados que empiezan a ser protagonistas de una economía capitalista, en que la producción, la distribución y el consumo de ciertos bienes y servicios informativos pertenecen a entes organizados en forma de sociedades cuyas acciones pueden pertenecer a empresas de distintos sectores. Pese a todo, si hay una singularidad en las empresas de comunicación es que la producción del mensaje influye en el mensaje. Y ése, además de los cambios más contemporáneos en el sector audiovisual de nuestro país, es la razón que lleva a estudiar la concentración.

Existen criterios opuestos según la perspectiva empresarial y teórica que se contemple. En diversos foros, los propietarios de medios han defendido que los niveles de concentración informativa en España no son preocupantes al ser inferiores a los de otros países del entorno, aunque la percepción sea diferente. Esta antítesis se fundamenta en las características intrínsecas del sector español que presenta unos índices de 
difusión y lectura inferiores a otros países de la Unión Europea. Consideradas ambas posturas en términos relativos, las ratios denotan que el nivel de concentración se acentúa, máxime si se pondera la ligazón del binomio competencia económica-competencia informativa, su traducción en los principios configuradores y la posterior plasmación de éstos en la línea informativa del medio, a veces dual, sin olvidar la capacidad de influir en la opinión pública en sintonía con criterios políticos.

En síntesis, y según lo expuesto, la concentración empresarial de medios de comunicación es un fenómeno complejo y su estudio, fundamentado en un método concreto, debe conjugar, al menos, las siguientes variables para conseguir una visión poliédrica, pero ajustada, tanto del proceso como de la resultante final:

- $\quad$ El tamaño de los grupos multimedia, que puede garantizar o hipotecar la expresión de la diversidad social.

- $\quad$ La posibilidad de cuantificar y describir estos procesos de crecimiento externo.

- La relevancia y causas que motivan los procesos de concentración.

- La legislación y los diversos factores jurídicos y administrativos, tanto nacionales como supranacionales, que inciden en los procesos de los medios.

- La perspectiva estrictamente económica y empresarial de la operación.

- La aparición de un oligopolio por el lado de la oferta de la información, que puede resultar compatible con los fines de las empresas protagonistas, entendidos éstos como máxima difusión informativa y obtención de beneficio" (Pérez de Armiñán, 2000: 223).

- $\quad$ El tratamiento informativo dado por los distintos medios al proceso.

- La concentración como factor que enriquece la producción informativa o, al contrario, como elemento que motiva la uniformización y devaluación de los mismos.

- La incidencia de la concentración en los principios configuradores y su influencia en la línea editorial que puede, o no, adecuarse a aquéllos.

- La concentración, como proceso de cambio, que puede beneficiar la libertad de los ciudadanos.

- La concentración como factor que puede perturbar o poner en peligro la independencia y el conveniente pluralismo informativo. 
- $\quad$ "La repercusión en el receptor que puede, o no, ver afectada su capacidad de elección entre medios dispares, con lo que hacemos referencia a la actitud del público y, en concreto, la de los destinatarios directamente afectados por la concentración” (Iglesias, 2005: 38).

\section{Referencias bibliográficas}

Borges, J. L. (2004): “Funes, el memorioso”, en Ficciones, Barcelona: Destino.

Buchanan, J. M. (1979): What should economists do? Indianapolis: Liberty Press.

Campos Freire, F. (2007): "Los principales grupos mundiales de medios de comunicación siguen siendo negocios de familia”, Zer, Revista de estudios de comunicación / komunikazio ikasketen aldizkaria, núm. 22, pp. 141-166.

Corominas Piulats, M.; Moragas Spà, M. de (2002): Informe de la comunicació a Catalunya 2002, Barcelona: Institut de la Comunicació (UAB).

Descartes, R. (1980): Discurso del método, Buenos Aires: Aguilar.

Giner, S. (1988): Sociología, Barcelona: Península.

Harada, E. (2005): “Ciencia, lenguaje y pragmática en la filosofía de Popper”, Razón y Palabra, núm. 46, [en línea], http://www.cem.itesm.mx/dacs/publicaciones/logos/anteriores/n46/eharada.html, 5 de enero de 2010.

Iglesias, F. (2005): Concentración y pluralismo en la radio española, Pamplona: EUNSA.

J. M. C. (15 de noviembre de 2000): “ $A B C$, segundo diario más leído e influyente de España, según el 'Herald Tribune’”, $A B C$, p. 87, [en línea], http://hemeroteca.abc.es/nav/Navigate.exe/hemeroteca/madrid/abc/2000/11/15/087.htm, 5 de enero de 2010.

Kerlinger, F. N.; Lee, B. H. (2001): Investigación del comportamiento. Métodos de Investigación en Ciencias Sociales, México: Mc Graw Hill.

Lakatos, I. (1971): “History of Science and its Rational Reconstruction”, Boston Studies in the Philosophy of Science, VIII.

Latorre Timoneda, E., Rubio, T. A. (1965): Psicología, lógica y ética, Madrid: Juan Bravo.

Llorens Maluquer, C. (2001): Concentración de empresas de comunicación y el pluralismo: la acción de la Unión Europea, Barcelona: UAB, [en línea], http://www.tdcat.cesca.es/TDCat-0111102-124855/, p. 13, 5 de enero de 2010.

McQuail, D. (1992): Media perfomance: mass communication and public interest, London: Sage.

Medina Laverón, M. (2005): Estructura y gestión de empresas audiovisuales, Pamplona: EUNSA.

Muñoz, J.; Güell, M.; Marías, I. (2001): Praxis de la Filosofía I, Barcelona: Octaedro.

Nieto, A.; Iglesias, F. (2000): La empresa informativa, Barcelona: Ariel. 
Pérez de Armiñán, C. (2000): “La concentración de empresas informativas”, en Táuler, M.; Población, J. I. (eds.): Estudios de empresa informativa. Homenaje al profesor José Tallón, Madrid: Departamento de Periodismo IV (Empresa Informativa), Facultad de Ciencias de la Información (UCM), pp 223-233.

Pérez Serrano, M.J. (2006): La concentración de medios en España. Análisis de casos relevantes en radio, prensa y televisión, Madrid: Tesis inédita (UCM).

Pérez Serrano, M.J. (2007): "La concentración de medios de comunicación. Aproximación teórico-práctica bajo la perspectiva bifocal de defensa de la competencia y pluralismo”, en Egúzquiza, I; Vidal, V. (coord.): La ética y el derecho de la información en tiempos del postperiodismo, Valencia: Fundación COSO, pp. 465-486.

Popper, K. R. (1997): El cuerpo y la mente, Barcelona: Paidós.

Rodríguez de Rivera, J. (2006): “Metodología (como metateoría de métodos y metódicas)", Madrid: Departamento de Ciencias Empresariales (UA), [en línea], http://sunwc.cepade.es/ jrivera/bases_teor/episteme/metodolog/metodologia.htm, 5 de diciembre de 2009 .

Stammler, R. (1930): Filosofía del Derecho, Madrid: Reus.

Suppe, F. (ed.) (1977): The Structure of scientific theory, Urbana: University of Illinois Press.

Medina Laverón, M. (2005): Estructura y gestión de empresas audiovisuales, Pamplona: EUNSA. 
